\title{
PROJECT-BASED LEARNING IN DESIGN AND MULTIMEDIA IN HIGHER EDUCATION: AN INTERACTIVE TIMELINE DEVELOPED IN COLLABORATION
}

\author{
M. Figueiredo', V. Alves' ${ }^{2}$, C. Lourenço ${ }^{3}$, V. M. Alves ${ }^{3}$, M. Bernardo ${ }^{4}$, N. Carapito ${ }^{3}$ \\ ${ }^{1}$ School of Education of Viseu and CI\&DEl, Polytechnic of Viseu (PORTUGAL) \\ ${ }^{2}$ School of Technology and Management of Viseu and CISeD, Polytechnic of Viseu \\ (PORTUGAL) \\ ${ }^{3}$ School of Management and Technology of Viseu, Polytechnic of Viseu (PORTUGAL) \\ ${ }^{4}$ School of Technology and Management of Viseu, Polytechnic of Viseu, and Instituto de \\ Telecomunicações (PORTUGAL)
}

\begin{abstract}
Project-based learning (PBL) is gaining relevance in higher education, due to its potential for rich learning experiences, providing opportunities for students to participate in real problem-solving and knowledge construction in authentic professional contexts. This paper presents an instance of PBL in a specific bachelor's programme - Multimedia Technologies and Design. The results are analysed considering Krajcik and Shin's six hallmarks of PBL: a driving question, the focus on learning goals, participation in educational activities, collaboration among students, the use of scaffolding, and the creation of tangible artifacts. Specificities of these features in Multimedia Design are also addressed.
\end{abstract}

Keywords: pedagogy, project based-learning, higher education, multimedia design.

\section{INTRODUCTION}

Higher education institutions are increasingly focused on providing students with both hard skills, such as professional knowledge and skills [1], and soft skills, including problem-solving and teamwork [2]. It is suggested that students should be provided with the opportunity to participate in real problem-solving and knowledge construction in authentic professional contexts. One way to achieve this goal is through project-based learning (PBL). In this paper, a particular PBL experience is described and analysed. The purpose is to share the solutions and limitations that were encountered, and to contribute to the adoption of relevant PBL in higher education, including in multimedia programmes where it is recommended [3]. In pedagogy, local solutions are needed because there are few context-independent approaches. As Clegg et al. mention, "we need to take account of (...) local conditions and the range of possibilities to particular pressures, rather than rely on over-deterministic accounts of global tendencies" [4, p. 40].

For the celebration of its $40^{\text {th }}$ anniversary, the Polytechnic Institute of Viseu (IPV) challenged its community to develop an interactive timeline that would present the history of the institution in the cities of Viseu and Lamego, to the public. The coordinator of the Multimedia Technologies and Design (TDM) [5] bachelor's degree took on the challenge and was responsible for the interface between the students and the IPV's task force for the commemorations. The integration of the endeavour in the programme was managed as a project in the scope of a second-year course, 'Interactive Content', with the participation of the respective teaching staff. Due to the pandemic situation, all interactions occurred through digital means, mainly via Zoom platform.

The initiative took the form of PBL, since it was a learning process in which students were engaged in working on an authentic project and the development of a product [6]. The IPV's task force assumed the role of "the client" throughout the process. Students developed their proposals in close communication with the client, with several rounds of feedback and development.

This paper reports on that process, looking into records and artifacts produced by students, teachers, and the client along the semester. The results are discussed according to Krajcik and Shin's [7] six hallmarks of Project-Based Learning, which include the creation of artifacts that solve authentic problems. This feature distinguishes PBL from other student-centred pedagogies and requires learners to work together to find solutions to real problems in the process of knowledge integration, application, and construction [8]. 


\section{PROJECT CONTEXT}

IPV is public higher education institution in the inner middle-centre of Portugal. Four of its schools are in the city of Viseu: Education, Health, Agriculture, Technology and Management, and one in the city of Lamego: (also) Technology and Management. About 5,400 students and 400 teachers are involved in 81 programmes - bachelors and masters' degrees, as well as post-graduations and technicalprofessional training (EQF level 5) - in a multitude of qualification areas: teacher education, social work, nursing, community health, engineering, arts, design and multimedia, marketing, management, tourism, media studies, agriculture, public relations, computer sciences, and sports. This diversity is brought together by a common pedagogical approach of valuing active learning along with practical experiences in real contexts through collaboration with local and regional stakeholders, enterprises, civil society, schools, and communities [9]. Most programmes are professionally oriented, in line with the mission of the polytechnic higher education system [10]. The education ecosystem is also defined by its connection to research.

During its 40 years, the institution resorted to many spaces (twelve, as this project allowed to recognize) in Viseu and in Lamego. Some of them were adopted after the extinction or moving of other organizations, others were temporary or borrowed during restoration and construction works, and others have been built from the ground up. Most of the staff who experienced these movements and transformations is still on duty and many shown great interest in sharing their memories [11]. Also, the institution is a reference in both cities, and the history of the spaces that once accommodated IPV is a matter that is potentially interesting for the community. Due to the institution's regional orientation, many people in these cities participated in that history.

A task force created in the scope of the celebration of IPV's anniversary conceived the idea of creating an interactive application that allows to navigate through the locations, showing photos that reveal how the buildings, rooms, constructions, and restorations looked like, at the time, combined with dates and other information that contextualize the facts. This production targets the general public, which includes those who somehow lived the portraited reality and, as importantly, current students who have an opportunity to put in perspective the legacy and liveliness of the organisation where they chose to prepare their futures. This interest in this latter audience made it evident that it would make sense to involve students in the making of the artifact, both to ease a genuine appropriation and to potentiate the embedding of visions that are timely and in line with their peers' mental models.

By the time the initiative was proposed, there was the chance to adapt the assignment of one of the projects in 'Interactive Content', a 6 ECTS course in TDM's second curricular year, second semester, whose goals are in line with the production of the intended application. Alternatives such as resorting to one of the 'Integrated Projects' (four courses, along the programme) [5] or the final degree's 'Project' would imply reframing the task force's calendar, which was not convenient. The programme's coordinator and the two teachers responsible for 'Interactive Content' met with the task force, to reveal their interest in participating, and organised the process, which is described in the following section.

\section{WORKFLOW AND FEEDBACK LOOP}

The opportunity was introduced to students by the programme coordinator and the course's two teachers, in a class. The IPV's task force was presented as a "client", consistently with the vocabulary and mindset adopted in other projects. Students acknowledged that they were facing a real problem and that the outcome was important to the client. They also became aware that the initiative would only make sense if the resulting product could be made available online. The reception was positive and an inclass meeting with the client was scheduled. The 38 students organised themselves in 16 groups of two or three members.

This project did not require students to research and compile the contents to include in the product. The client provided them with the following materials: the list of events to include in the timeline - including their title, date, short description, location(s); and respective photos, with captions. To ease the perception of the variations in the extension of resources available for each event, namely the number of photos and implied locations, a table was also provided, evidencing the distribution.

On the other hand, students were to develop solutions for navigating through the events, by date and/or location. The challenges included: the fact that the distribution of the events over time is not uniform (e.g., some years have more than one event, and in some periods there are no events); there are several events that happened in the same location; some locations are very close to each other while the distance between locations in Viseu and Lamego is about $60 \mathrm{~km}$; older photos are very low quality to 
current standards, with small resolutions and requiring thorough image processing to correct several graphical issues; the amount of information available for each event is not uniform, in terms of the number of locations implied, the length of the text that represents their addresses, the number of available photos (as mentioned above), and the extension of the description. Also, the design options should be mobile-friendly. Regarding technology, and in accordance with the course's syllabus, it was set that the timeline should consist of an HTML5 Canvas and JavaScript code, for embedding on a Web page. For the development, students could use Adobe Animate.

Starting from the session in which the client presented the project briefing to the whole class, the solutions were developed using an agile approach [12], [13], allowing for an incremental and iterative production [14]-[18]. This approach implies that, at any given time, designers shall not assume that they have a perfect understanding of the client's needs nor of how users will perceive the resulting production. Instead, there is the need to build the solution step by step, supported by recurrent evaluation, systematically adapting the implementation or the design itself, according to the intended objectives. It is also anticipated that clients' initial perception of their own needs is imperfect or incomplete, and that requirements evolve, as solutions become available and support new perspectives.

All stakeholders were aware of the complexity of the proposal and that it would be instrumental to provide students with guidance beyond class time. As such, they arranged several meetings involving each group, the client, and the programme coordinator who played the role of facilitator [19], [20] and expert in interaction design. These meetings became core to the workflow because they consisted of intense design sessions, in which students had the chance to have expedite assistance in both leveraging their ideas and fixing possible issues, while also having a direct, albeit mediated, contact with the client.

For each group, there was a minimum of three meetings, from the middle of March until the beginning of May. In the first two rounds, meetings lasted between $1 \mathrm{~h} 30$ and $3 \mathrm{~h}$. In the final round, meetings lasted around $1 \mathrm{~h} 30$. Some groups had extra sessions in-between these three. Overall, every group had at least $4 \mathrm{~h} 30$ of discussion of their work with some groups totalling 9 hours.

As part of the production cycle, one of the groups' first activities consisted of researching existing solutions for timelines. These students were already educated not to perform a strict benchmarking of "competing" projects but to gather inputs from disparate domains [21]. The result of that exercise, combined with the students' own insights constituted the matter for the debuting sessions.

A fundamental aspect in these sessions was that the facilitator explicitly avoided to present the groups with ideas for their respective solutions. Even in the cases when groups felt more difficulties, including in the initial ideation phases, the facilitator role was to lead students to acknowledge their ability to advance with plausible solutions. The underlying principle was that students should still be the genuine authors of their projects, aiming at their empowerment and identification with the solution.

It is worth clarifying that these students had former training on ideation processes and managing creativity, both as explicit content in the scope of foundational courses and as part of their projects in many other courses. Still, it became manifest that producing ideas in a timely manner is a practice that requires repetition and development of the awareness that it is an objective task, for which there are very effective methods and techniques.

That said, the most prevalent difficulties were content adaptation to the medium, lack of consistency in several dimensions of the solution, and the design of the interfaces. Again, these are topics with which students were already familiar but that require as many opportunities as possible to appreciate from different perspectives and to eventually internalize and embed in one's routines. By no means the point of this reasoning is to argue that this experience "solved" the students' needs regarding such issues. On the contrary, the argument is that learning, particularly of such matters, is not binary - and that the more and richer the occasions to exercise, the better the chances to grow expertise. While this is not exactly a revelation, it is relevant to recognize that the strict achievement of curricular commitments is hardly enough to reach such goals.

\section{CRITICAL ANALYSIS OF THE PROCESS}

As so many other approaches that consist of close support to students [22], this was a very timeconsuming endeavour. It was also a project that was not possible to circumscribe to the formal limits of strictly curricular commitments. It demanded that students were willing to engage with entities other than their teachers. In this programme, students have a substantial load of work to be completed in between classes, regarding the several courses in the semester, and solicitations such as this require 
determination and compromises that may not be easy to manage. Circumstantially, this experience occurred during the COVID-19 pandemic, which introduced other levels of complexity.

Although the groups succeeded according to the requirements that were reasonable to establish in the scope of the course's assignment, the polishing of a product to a level of excellence that matches the celebration of the institution, where the authors are learning their craft, had to be continued after the course, including after students received their grades.

The consistent participation of the facilitator and the readiness of the client's feedback became a main feature of the experience. It is noteworthy that a great proximity amongst the participants developed beyond what was foreseen. Although students were encouraged to work close to the facilitator and client, and some of the meetings were scheduled by the course teachers, there were solicitations out of the schedule and sessions consistently lasted longer than anticipated, because they were productive, typically assuming a form closer to design workshops [23] than to design critiques [24], and clearly diverting from mere presentations, tutoring time, or evaluation meetings.

For the success of this dynamic, the performance of the client was also instrumental. During each session, the client followed the developments but did not interfere in the design process unless requested to do so. Doing so, the client did not add entropy to the system and allowed students to develop their work supported by the facilitator. On the other hand, the fact that the client attended to the projects' development and was aware of the trade-offs associated to each solution contributed for more informed and expedite feedback. This arrangement was defined during preliminary meetings between the client, the facilitator, and the course teaching staff. The field of expertise of the person assuming the client's role is educational sciences, so it became easy to share the goals, empathise, and play along with the strategy.

Although this client's behaviour is not representative of what students should expect in the market, this experience allowed for learning routines when dealing with clients. That is, it was fruitful to have a genuine client with a real-world problem who, nonetheless, was fully present and willing to cooperate in a learning process, behaving as "invisible" while not explicitly requested to intervene. One of the dimensions of intervention of the facilitator was to model the discourse, the timings, and type of feedback that students directed to the client. In cases where a correction was appropriate, the client would abide while the facilitator had the chance to complete the exposition of the issue at stake and until students could reformulate their solicitation. Apart from that, the client acted strictly as such, not interfering in the design process and conversations between the students and the facilitator. Still, considering that the workflow allowed for prompt and systematic feedback from the client - and that, in between meetings, the client and facilitator reviewed the projects' progresses in the light of the client's intend goals -, it is proper to classify this experience also as participatory design [23].

Finally, it seems fair to argue that the commitment that students witnessed from the other stakeholders, as focused on serving the students empowerment as in the outcome, contributed for their own engagement. While it is natural that students would expect that attitude from the course's teaching staff, it might have been more stirring to perceived it coming from people who did not have the same formal obligation.

\section{PRODUCT: THE TIMELINES}

Consistently with the adopted production methodology, the timelines evolved through incrementally enhanced prototypes [15], [18], [23], [25]. Students were already acquainted with this practice, from former courses and projects, and were able to focus on their design options without getting delayed by the task itself.

Students started by creating paper prototypes [18], [25], as those illustrated in Fig.1. As expected, this basic form of prototyping was very effective. Firstly, it allowed designers to quickly give shape to their emerging ideas and complete them as they got a tangible grasp of the system that they were building. At this level, corrections and new attempts are easily executed because the principles are virtually the same as those from any everyday drafting exercise. Secondly, these prototypes were instrumental to discuss the solutions with the facilitator and the client.

The low fidelity proved the advantage of driving stakeholders away from the discussions of (e.g., graphical) details and focusing on system features and the accomplishment of the client's needs. The quality of the drawings might have eased readability, but the relevance of this tool stems from the representation of the interface components and how users would interact with them. 

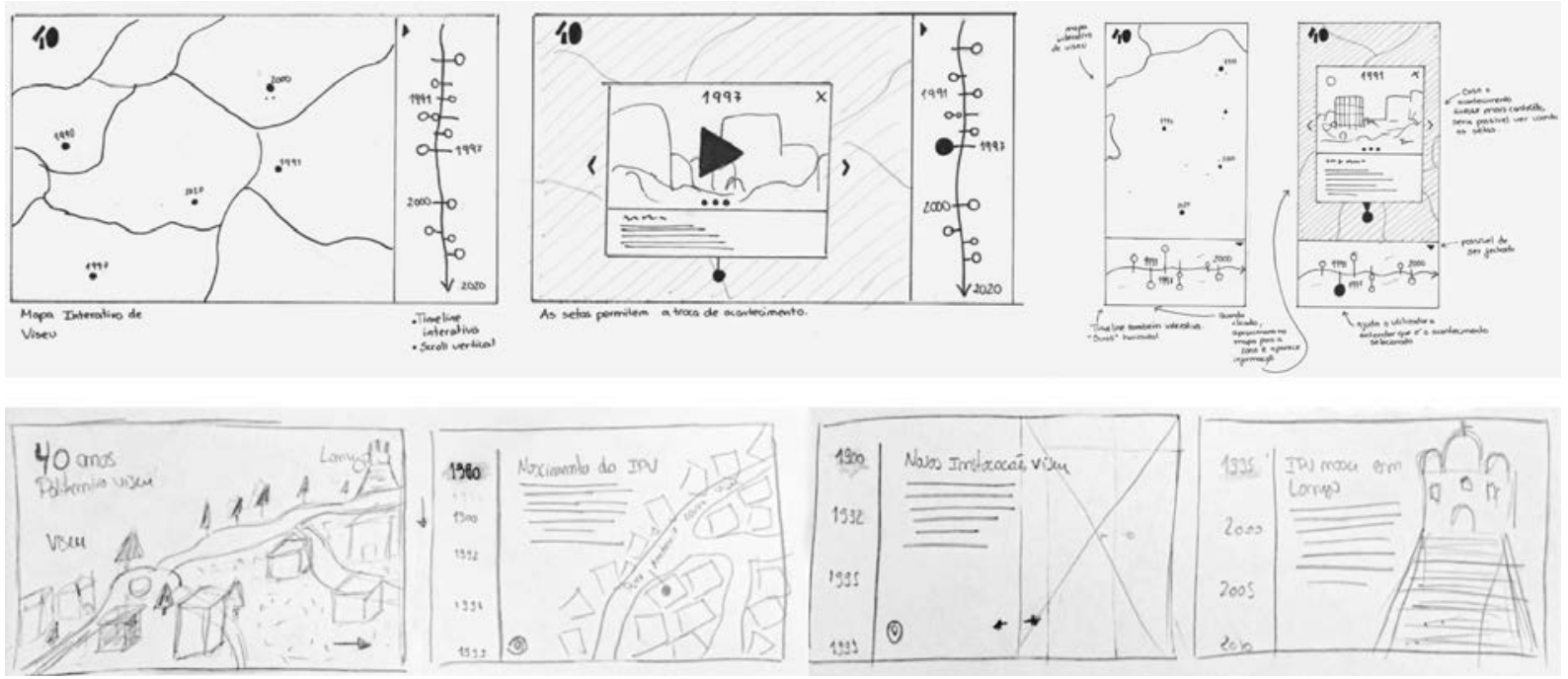

Figure 1. Two examples of early paper prototypes.

Fig. 2 shows a selection of the main screens from several groups' prototypes, further iterated during the meetings, already using digital means to execute the representations. The mosaic allows to acknowledge that groups developed noticeably distinct solutions.
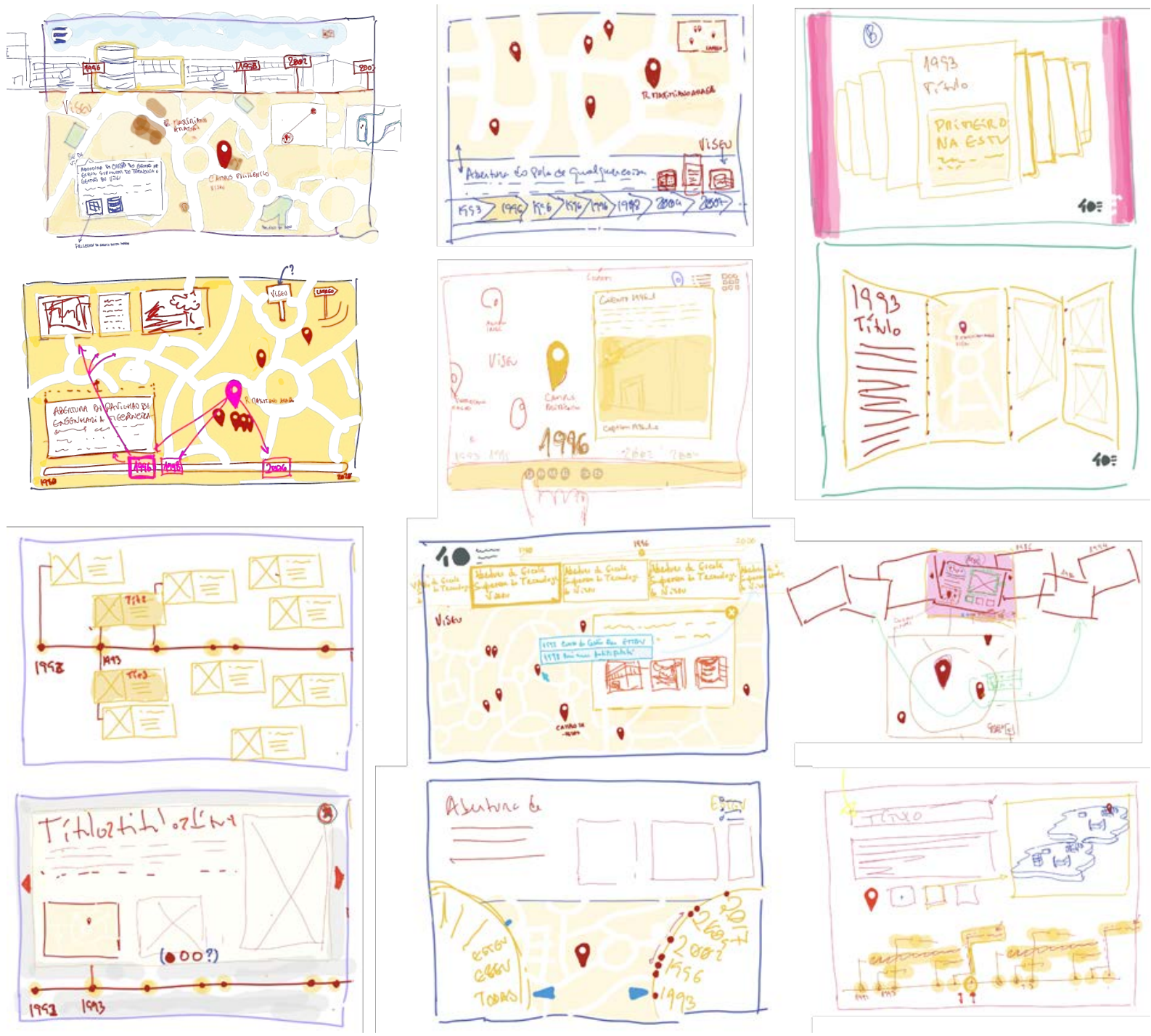

Figure 2. Some main screens from the low fidelity prototypes, developed during the meetings. 
Fig. 3 exhibits a selection of screens characterising the solution that is available online, at http://193.137.7.33/ timeline40anos. This is the timeline that became associated with the celebrations.
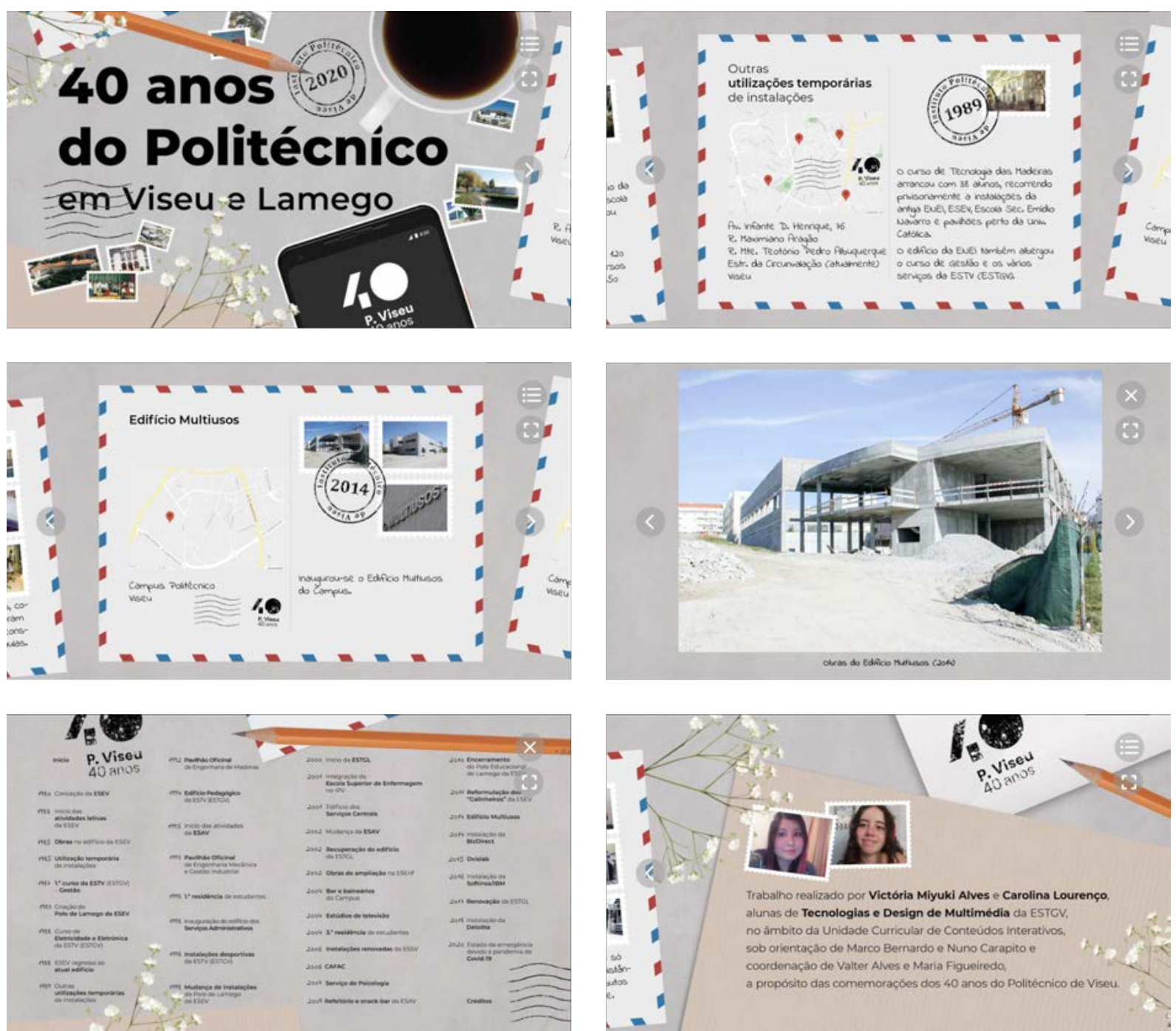

Figure 3. Sample screens of the published timeline.

\section{THE EXPERIENCE AS PBL}

In this section, for a more detailed analysis, the experience is framed according to Krajcik and Shin's [7] six key-features of PBL: a driving question or problem to be solved, the focus on learning goals, participation in educational activities, collaboration among students, the use of scaffolding, and the creation of tangible artifacts.

The first, 'a driving question or problem to be solved', assumed two steps. The challenge set by the task force already met this criterion - but the highlight goes to the way the programme coordinator and the course's teaching staff reworked that challenge before presenting it to the students. That adaptation was essential to ensure that students were presented with a feasible assignment, through which the several tasks involved gained continuity and coherence. Besides the careful design of the assignment, during the meetings, the client's interventions, as mentioned, didn't deviate from the initial challenge and the feedback provided was also intended to keep the groups on track regarding the driving question, by "looping" back to it.

The second key-feature, 'the focus on learning goals', was achieved through the groundwork, by the programme's coordinator and the teaching staff, guaranteeing the alignment of the assignment specification with the programme and course's objectives. The project required that students used knowledge and skills fundamental to their professional profile, as well as critical thinking, selfmanagement, and collaboration. This also connects with the third key-feature, 'participation in 
educational activities', as students had to participate in design and developing practices that are central to expert performance in the multimedia field. As the groups presented their ideas, it was evident how the project allowed them to make choices - about the product, but also about how they worked and how they used their time. The meetings were crucial to assure that groups reflected on the process and revised their ideas and solutions.

As described, the process was strongly collaborative, accomplishing the fourth key-feature, 'collaboration among students' and other actors involved. The engagement between all participants was key along the productions, mirroring the complex social situation of future professional challenges. In a significant difference from a professional context, in this process, scaffolding was part of those collaborations, as a support that enabled the still unexperienced students to solve a problem which would be beyond their unassisted efforts [26]. 'Scaffolding', the fifth key-feature of PBL, provides a temporary structure to assist a learner in a task, until it becomes possible to reduce or remove it. The framework that served as scaffold, in this case, refers to the familiar context of the classes and work processes students were used to, and to the intervention of the facilitator who managed expectations and feedback according to students' skills and difficulties.

The final key-feature refers to the 'creation of tangible artifacts.' The creation of the interactive timeline was the aggregator of the whole process. Its several iterations were the basis of the discussions, and learning was mainly connected to its dimensions - design of the interface, navigation, content selection and processing, etc. Because the timeline was to become publicly accessible as part of the anniversary celebration, the product was more than the representation of the groups' learning, it was a showcase of the professional competences of its authors and, by extension, of the programme quality.

\section{CONCLUSIONS}

The paper describes the exploration of an opportunity to fit a multimedia design experience, conducted as PBL, as part of the cast of assignments in a second-year course of a multimedia technologies and design bachelor's degree. The project consisted of the creation of an interactive timeline, for the celebration of the fortieth anniversary of the institution hosting the programme. The main protagonists were the course students and their two teachers, the project's proponent - conveniently referred to as "the client" -, and a facilitator who is a teacher in that same programme but was not part of the course's teaching staff. The facilitator field of expertise is interaction design, being also knowledgeable in topics and technologies addressed in the course. The client, besides being a member of the task force created for the celebration, belongs to the teaching staff of another school in the same institution, specializing in educational sciences.

The dimension of the project, compared to the contribution the course could lend, both regarding the time span and scope, demanded that the stakeholders designed a strategy that led to the expected results while serving the course's syllabus and providing a rewarding experience to students. The workflow was characterised by consistent support from the facilitator, through a series of online meetings (as the COVID-19 pandemic situation obliged) where the client was also present. This proximity also contributed to the effectiveness of the process because the client was always in context and could provide prompt and informed feedback. A protocol between the client and the facilitator permitted that their roles did not blend, namely in terms of the students' perception. The presence of both these stakeholders, and the dynamics between them, worked as an accelerator for the work progress.

Students idealised and implemented interesting solutions, significantly diverse in nature. Apart from its learning virtues, the adopted workflow allowed for the accommodation of the client's challenge as part of the course's set of assignments. Nonetheless, the perfecting of a product before being made available online, required that some work was still carried out after the course was complete.

Overall, the learning experience was perceived as most valuable by all stakeholders. In addition to the topics introduced in the course, students needed to mobilize distinct knowledge from their previous courses. This process concurred to strengthen the idea that, at least in this domain, understanding concepts and techniques in a particular context is not always synonymous with apprehending them and becoming able to transpose them to new contexts. It is relevant that students have opportunities, as abounding and diverse as it is feasible to fit in their education, to review their knowledge from as many different angles as possible, and to repeat its application until it becomes second nature and allows them to focus on excellence and self-actualisation. 


\section{ACKNOWLEDGEMENTS}

This work was funded by National Funds through the FCT - Foundation for Science and Technology, I.P., within the scope of the project Ref. UIDB/05507/2020. Furthermore, we would like to thank the Centre for Studies in Education and Innovation (CI\&DEI), the Research Centre in Digital Services (CISeD), and the Polytechnic of Viseu, for their support. This work was also supported by the partnership between IPV-Institute Polytechnic of Viseu and CGD-Caixa Geral de Depósitos.

\section{REFERENCES}

[1] J. S. Vogler, P. Thompson, D. W. Davis, B. E. Mayfield, P. M. Finley, and D. Yasseri, 'The hard work of soft skills: augmenting the project-based learning experience with interdisciplinary teamwork', Instr. Sci., vol. 46, no. 3, Art. no. 3, 2018, doi: 10.1007/s11251-017-9438-9.

[2] Z. Sokhanvar, K. Salehi, and F. Sokhanvar, 'Advantages of authentic assessment for improving the learning experience and employability skills of higher education students: A systematic literature review', Stud. Educ. Eval., vol. 70, p. 101030, 2021, doi: 10.1016/j.stueduc.2021.101030.

[3] N. Zagalo, 'Transdisciplinaridade da multimédia', in Multimédia, Novos Média e Média Digitais, N. Zagalo, Ed. Aveiro: UA Editora, 2021, pp. 7-28. Accessed: Jun. 21, 2021. [Online]. Available: https://ria.ua.pt/handle/10773/31419

[4] S. Clegg, A. Hudson, and J. Steel, 'The emperor's new clothes: globalisation and e-learning in higher education', Br. J. Sociol. Educ., vol. 5, no. 1, Art. no. 1, 2003.

[5] 'Multimedia Technologies and Design', Escola Superior de Tecnologia e Gestão de Viseu, 2021. http://www.estgv.ipv.pt/estgv/?v=199 (accessed May 13, 2021).

[6] C.-H. Chen and Y.-C. Yang, 'Revisiting the effects of project-based learning on students' academic achievement: A meta-analysis investigating moderators', Educ. Res. Rev., vol. 26, pp. 71-81, 2019, doi: 10.1016/j.edurev.2018.11.001.

[7] J. S. Krajcik and N. Shin, 'Project-Based Learning', in The Cambridge Handbook of the Learning Sciences, 2nd ed., R. K. Sawyer, Ed. Cambridge: Cambridge University Press, 2014, pp. 275-297. doi: 10.1017/CBO9781139519526.018.

[8] L. Helle, P. Tynjälä, and E. Olkinuora, 'Project-Based Learning in Post-Secondary Education Theory, Practice and Rubber Sling Shots', High. Educ., vol. 51, no. 2, Art. no. 2, 2006, doi: 10.1007/s10734-004-6386-5.

[9] M. P. Figueiredo et al., 'Professional Development for Higher Education Teaching Staff: an Experience of Peer Learning in a Portuguese Polytechnic', in INTED2021 Proceedings, 2021. doi: 10.21125/inted.2021.

[10] C. V. Urbano, 'A (id)entidade do ensino superior politécnico em Portugal: da Lei de Bases do Sistema Educativo à Declaração de Bolonha', Sociol. Probl. E Práticas, no. 66, Art. no. 66, 2011.

[11] V. Alves, L. Basílio, and M. P. Figueiredo, 'Objetos, sítios e memórias de 40 anos do Politécnico de Viseu: processos e aprendizagens de uma exposição virtual', in Livro de Resumos do XV Congresso da Sociedade Portuguesa de Ciências da Educação Liberdade, Equidade e Emancipação', Porto, 2020, pp. 329-330.

[12] K. Beck et al., 'Manifesto for Agile Software Development', Manifesto for Agile Software Development, 2001. http://agilemanifesto.org/ (accessed May 13, 2021).

[13] S. Kiv, S. Heng, M. Kolp, and Y. Wautelet, 'Agile Manifesto and Practices Selection for Tailoring Software Development: A Systematic Literature Review', in Product-Focused Software Process Improvement - 19th International Conference, PROFES 2018, Wolfsburg, Germany, November 2830, 2018, Proceedings, 2018, vol. 11271, pp. 12-30. doi: 10.1007/978-3-030-03673-7_2.

[14] M. Korsaa, R. Olesen, and O. Vinter, 'Iterative Software Development - A Practical View', Jan. 2001.

[15] W. Lidwell, K. Holden, and J. Butler, Universal principles of design: 125 ways to enhance usability, influence perception, increase appeal, make better design decisions, and teach through design, Rev. and Updated. Beverly, Mass: Rockport Publ, 2010.

[16] C. Larman and V. R. Basili, 'Iterative and incremental developments. a brief history', Computer, vol. 36, no. 6, pp. 47-56, Jun. 2003, doi: 10.1109/MC.2003.1204375. 
[17] A. Cockburn, 'Using Both Incremental and Iterative Development', 2008.

[18] H. Sharp, J. Preece, and Y. Rogers, Interaction design, 5th ed. Indianapolis, IN: John Wiley and Sons, 2019.

[19] S. Gibbons, Facilitation 101, (2020). Accessed: May 13, 2021. [Online Video]. Available: https://www.nngroup.com/videos/facilitation-101/

[20] S. Gibbons, A 4 Minute UX Workshop Facilitator's Guide, (2018). Accessed: May 13, 2021. [Online Video]. Available: https://www.nngroup.com/videos/ux-facilitator-guide/

[21] M. Lewrick, P. Link, and L. J. Leifer, The design thinking playbook: mindful digital transformation of teams, products, services, businesses and ecosystems. Hoboken: Wiley, 2018.

[22] B. Condliffe, 'Project-Based Learning. A Literature Review', MDRC, 2017.

[23] B. Martin and B. M. Hanington, Universal methods of design: 100 ways to research complex problems, develop innovative ideas, and design effective solutions, Digital ed. Beverly, MA: Rockport Publishers, 2012.

[24] S. Gibbons, 'Design Critiques: Encourage a Positive Culture to Improve Products', Nielsen Norman Group, 2016. https://www.nngroup.com/articles/design-critiques/ (accessed May 13, 2021).

[25] S. Greenberg, S. Carpendale, N. Marquardt, and W. Buxton, Eds., Sketching user experiences. Amsterdam; Boston: Elsevier/Morgan Kaufmann, 2012.

[26] D. Wood, J. S. Bruner, and G. Ross, 'The role of tutoring in problem solving', J. Child Psychol. Psychiatry Appl. Discip., no. 17, Art. no. 17, 1976. 